$01,07,11$

\title{
Влияние высоких давлений на формирование новых соединений в сплаве $\mathrm{Al}_{86} \mathrm{Ni}_{2} \mathrm{Co}_{6} \mathrm{Gd}_{6}{ }^{*}$
}

\author{
(C) С.Г. Меньшикова ${ }^{1}$, В.В. Бражкин ${ }^{2}$ \\ ${ }^{1}$ Удмуртский федеральный исследовательский центр УрО РАН, \\ Ижевск, Россия \\ ${ }^{2}$ Институт фоизики высоких давлений РАН, \\ Москва, Троицк, Россия \\ E-mail: svetlmensh@mail.ru
}

Поступила в Редакцию 8 июля 2021 г.

В окончательной редакции 13 июля 2021 г.

Принята к публикации 16 июля 2021 г.

Методами рентгеноструктурного анализа и электронной микроскопии исследованы структура, элементный и фазовый состав эвтектического сплава $\mathrm{Al}_{86} \mathrm{Ni}_{2} \mathrm{Co}_{6} \mathrm{Gd}_{6}$ (здесь и далее по тексту at.\%) при затвердевании расплава от $1500^{\circ} \mathrm{C}$ со скоростью $1000^{\circ} \mathrm{C} / \mathrm{s}$ под высоким давлением 3 и $7 \mathrm{GPa}$. Затвердевание расплава под высоким давлением приводит к изменению фазового состава сплава и формированию аномально пересыщенного твердого раствора $\alpha$-Al $(\mathrm{Gd})$. При давлении $7 \mathrm{GPa}$ синтезированы новые фазы: $\mathrm{Al}_{3} \mathrm{Gd}^{*}$ (по типу $\mathrm{Al}_{3} \mathrm{U}$ ), содержащей Со и $\mathrm{Ni}$, со структурой примитивного куба (сР4/2) с параметром решетки $a=4.285 \pm 0.002 \AA$ и $\mathrm{Al}_{8} \mathrm{Co}_{4} \mathrm{Gd}^{*}$ (по типу $\mathrm{Al}_{8} \mathrm{Cr}_{4} \mathrm{Gd}$ ) с тетрагональной структурой $(\mathrm{t} I 26 / 1)$ с параметрами $a=8.906 \pm 0.003 \AA$ и $c=5.150 \pm 0.003 \AA$. Структура всех полученных образцов однородная, плотная, мелкодисперсная, без усадочных раковин и пор. Средняя микротвердость образцов высокая за счет твердорастворного и дисперсионного упрочнения.

Ключевые слова: высокое давление, микроструктура, фаза, микротвердость, расплав.

DOI: 10.21883/FTT.2022.02.51924.32s

\section{1. Введение}

Получение материалов с заданными структурой и свойствами при известных термодинамических параметрах (температуре, давлении, химическом составе) является одной из основных и наиболее актуальных задач физики и химии конденсированного состояния. Многокомпонентные стеклообразующие сплавы на основе алюминия типа Al-ПМ-Р3М (ПМ-переходный металл, РЗМ-редкоземельный металл) имеют перспективы практического применения как конструкционные материалы. Такие сплавы, содержащие РЗМ в комплексе с 3d-металлами, обладают высокими механическими свойствами и высокой термической стабильностью. Сочетание различных экстремальных воздействий (сверхбыстрое и быстрое охлаждение из расплава, сверхвысокие и высокие давления и температуры, сверхсильные и сильные электрические и магнитные поля и т.п.) позволяет расширить области метастабильных состояний, получать новые соединения, новые модификации известных соединений, модифицировать структуру дефектов на микрои наноуровнях, т. е. получать материалы с разнообразной структурой: аморфной, квази- и нанокристалической и, соответственно, с разными свойствами $[1,2]$. Высокое давление (несколько $\mathrm{GPa}$ ) в сочетании с быстрым охлаждением $\left(10^{3}-10^{5 \circ} \mathrm{C} / \mathrm{s}\right)$ способствует синтезу новых

* Доклад на XXI Всероссийской школе-семинаре по проблемам физики конденсированного состояния вещества (СПФКС-21), Екатеринбург, 18-25 марта 2021 г. структур, а также является универсальным параметром исследования природы химической связи и атомных взаимодействий. Известно, что под воздействием высоких давлений в структуре сплавов, в зависимости от их исходного состояния, могут происходить различные изменения: расслоение исходно однородной аморфной фазы, формирование стабильных и метастабильных фаз [3-5]. Давление в процессе затвердевания влияет на структуру металлов и сплавов, улучшая их свойства благодаря увеличению центров кристаллизации и уменьшению микропор, а также способствует подавлению образования усадочных раковин. При быстром затвердевании расплава под высоким давлением можно ожидать увеличения взаимной растворимости компонентов, дробления и измельчения зерна, изменение механизмов кристаллизации и т. п. [6,7].

В сплавах типа Al-ПМ-РЗМ возможно формирование нескольких фаз-стеклообразователей $[1,8,9]$, конкуренция между которыми при зарождении приводит к образованию метастабильных фаз, а также способствует повышению аморфизующей способности сплавов. Цель настоящей работы - изучить возможность формирования новых фаз в сплаве $\mathrm{Al}_{86} \mathrm{Ni}_{2} \mathrm{Co}_{6} \mathrm{Gd}_{6}$ при быстром затвердевании его высокотемпературного расплава под высоким давлением.

\section{2. Материалы и методы исследования}

Слиток состава $\mathrm{Al}_{86} \mathrm{Ni}_{2} \mathrm{Co}_{6} \mathrm{Gd}_{6}$ получали сплавлением металлов в корундовых тиглях в печи Таммана. Исход- 

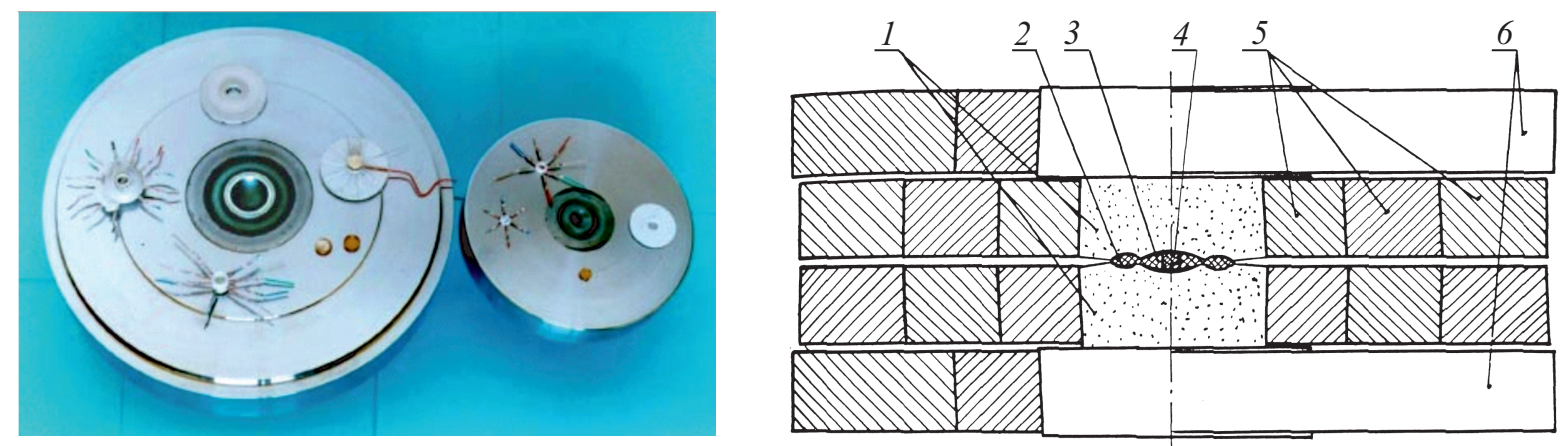

Рис. 1. Камера типа „тороид“. 1 - твердый сплав, 2 - тор, 3 - центральная часть в виде чечевицы, 4 - нагреватель и образец, 5 - стальные кольца, 6 - опорные плиты.

ными компонентами служили элементы с содержанием основного металла: алюминий — 99.999, никель 99.93, кобальт - 99.99 гадолиний - 99.9 масс.\%.

Технология приготовления сплава: нагрев $\mathrm{Al}$ до $800^{\circ} \mathrm{C}$ $\rightarrow$ введение $\mathrm{Ni}$, Co (повышение до $1050^{\circ} \mathrm{C}$ в течение $50 \mathrm{~min}) \rightarrow$ при $1050^{\circ} \mathrm{C}$ перемешивание корундовым стержнем;

$\rightarrow$ охлаждение до $850^{\circ} \mathrm{C}, \rightarrow$ ввод всего Gd (нагрев в течение $15 \mathrm{~min}$ до $\left.1020^{\circ} \mathrm{C}\right) \rightarrow$ перемешивание корундовым стержнем $\rightarrow$ выпуск в чугунную изложницу $d \sim 21 \mathrm{~mm}$.

Далее слиток 2 раза переплавляли в вакуумной печи для повышения однородности распределения легирующих элементов. Химический анализ слитка показал, что содержание основных компонентов соответствовало заданному составу в пределах $\pm 0.25 \%$ от номинального. Полученный слиток рассматривали как исходный образец.

Образцы для исследований получали под высоким давлением 3 и $7 \mathrm{GPa}$ в камере высокого давления типа „тороид“ [10] (рис. 1). Камера представляла собой запрессованные в стальные кольца плоские наковальни из твердого сплава. Средой, передающей давление, являлся катленит (алгетский камень). Основной принцип создания высокого давления в камере такой конструкции состоит в чередовании процессов сжатия и истечения среды, передающей давление. Сжатие исследуемых образцов осуществлялось пуансонами из твердого сплава. Истечение твердого вещества происходило через кольцевой зазор между пунсонами. Истечение вещества прекращается после достижения равновесия между силами давления в центральной части камеры и трения в кольцевом зазоре. Последующее увеличение нагрузки приводит к повышению давления только за счет сжатия твердой среды. Применение твердых материалов, а не жидких и газообразных, в качестве среды, передающей давление, позволяет повысить не только давление, но и температуру синтеза в эксперименте. Значения давления выбирали с учетом ранее выполненных работ для других сплавов такого же типа, Al-ПМ-P3М (80-90 at.\% Al) [11-13].

Охлаждение расплавов проводили со скоростью $1000^{\circ} \mathrm{C} / \mathrm{s}$, температура расплава перед закалкой состав- ляла $1500^{\circ} \mathrm{C}$. Нагрев и плавление проводили пропусканием переменного тока через образец, помещенный в тигель из гексагонального нитрида бора. Токоподводами служили пуансоны высокого давления. Значение температуры рассчитывали на основе показаний тиристора (тока, пропускаемого через образец). Давление было постоянным в ходе всего эксперимента. После охлаждения образца до комнатной температуры давление снимали до атмосферного. Фазовый состав образцов определяли методом рентгеноструктурного анализа на установках Дрон-6 в $\mathrm{Cu} K_{\alpha}$ и Дрон-3 в Со $K_{\alpha}$-излучении. Диапазон съемки $2 \theta$ составлял от 20 до $120^{\circ}$, шаг по углу $0.05^{\circ}$, время экспозиции $20 \mathrm{~s}$. Выбор режимов съемки производился исходя из необходимости достижения достаточной точности для определения углового положения дифракционных максимумов и интегральной интенсивности. Для обработки рентгенограмм (определения фазового состава, параметров решеток, пространственной группы фаз) использовали программу PHAN из пакета MIS\&A, а также программу „Топаз“. В программы вводили профили рентгенограмм исследуемых образцов, проводили их обработку и анализ. Для определения химического, элементного состава, морфологии и размера структурных составляющих сплава использовали системy Quattro S - Сканирующий Электронный Микроскоп (CЭM) со стандартным детектором DBS (детектор направленного обратного рассеяния) ABS/CBS. Ошибка в определении процентного содержания элементов в образцах не более 5\%. Анализ структуры проводили как в высоком, так и низком вакууме. Режим высокого вакуума - это обычный режим работы, традиционный для СЭМ. Режим низкого вакуума - режим естественной среды. Использовали трехступенчатую вакуумную систему: черновой вакуум обеспечивали форвакуумным насосом (Pre-Vacuum Pump, PVP), вакуум в камере поддерживали турбо-молекулярным насосом (Turbo Molecular Pump, TMP), а вакуум в области источника обеспечивал ионно-геттерный насос (Ion Getter Pump, IGP). В режиме среды низкого вакуума электронная колонна находилась под высоким вакуумом, а в камере образца - вспомогательный газ под давлением. Сходи- 
Таблица 1. Условия получения и фазовый состав образцов $\mathrm{Al}_{86} \mathrm{Ni}_{2} \mathrm{Co}_{6} \mathrm{Gd}_{6}$

\begin{tabular}{|c|c|c|}
\hline № & Условия получения & Фазовый состав \\
\hline 1 & Исходный образец & $\begin{array}{l}\left.\alpha-\mathrm{Al}(\mathrm{Gd}) \text { (куб., } \mathrm{cF} 4 / 1), \mathrm{Al}_{9} \mathrm{Co}_{2} \text { (мнкл., } \mathrm{mP} 22 / 1\right) \text {, } \\
\left.\mathrm{Al}_{3} \mathrm{Gd} \text { (гекс., } \mathrm{hP} 8 / 3\right), \mathrm{Al}_{3} \mathrm{Ni} \text { (ортр., оР16/2) }\end{array}$ \\
\hline 2 & $3 \mathrm{GPa}\left(1500^{\circ} \mathrm{C}\right)$ & $\alpha-\mathrm{Al}(\mathrm{Gd})$ (куб., $\mathrm{cF} 4 / 1), \mathrm{Al}_{4} \mathrm{CoNi} 2$ (куб., cI112/1) \\
\hline 3 & $7 \mathrm{GPa}\left(1500^{\circ} \mathrm{C}\right)$ & $\begin{array}{l}\alpha-\mathrm{Al}(\mathrm{Gd}) \text { (куб., сF4/1), } \\
\mathrm{Al}_{3} \mathrm{Gd}^{*}(\mathrm{Ni} / \mathrm{Co})\left(\text { по типу } \mathrm{Al}_{3} \mathrm{U}\right) \text { (куб., сР4/2), } \\
\left.\mathrm{Al}_{8} \mathrm{Co}_{4} \mathrm{Gd}^{* *} \text { (по типу } \mathrm{Al}_{8} \mathrm{Cr}_{4} \mathrm{Gd}\right)(\text { тетр., tI26/1) }\end{array}$ \\
\hline
\end{tabular}

мость системы СЭМ и рентгеновского детектирования (в частности, EDX - энергодисперсионная рентгеновская спектроскопия) на коротком рабочем расстоянии позволила провести высокоточный химический анализ при высоком разрешении поверхностных и подповерхностных характеристик. Дюраметрические измерения (твердость по Виккерсу, $H_{v}$ ) выполняли на микротвердомере ПМТ-3М, нагрузка $50 \mathrm{~g}$, выдержка $10 \mathrm{~s}$. Значения $H_{v}$ усредняли по 20 измерениям.

\section{3. Результаты и их обсуждение}

В табл. 1 представлены условия получения и фазовый состав исходного и полученных под высоким давлением образцов исследуемого сплава, определенный рентгеноструктурным анализом. На рис. 2 - представлена микроструктура (при различных увеличениях) и концентрационные карты распределения легирующих элементов $(\mathrm{Ni}, \mathrm{Co}, \mathrm{Gd})$ в образцах. В табл. 2-4 представлен полуколичественный элементный анализ структурных составляющих образцов.

На рис. 2, $a$ представлена микроструктура исходного слитка $\mathrm{Al}_{86} \mathrm{Ni}_{2} \mathrm{Co}_{6} \mathrm{Gd}_{6}$. В структуре присутствуют крупные первичные кристаллы фазы $\mathrm{Al}_{3} \mathrm{Gd}$ в виде пластин толщиной более $20 \mu \mathrm{m}$ разной длины (белые кристаллы на рис. $2, a)$, твердый раствор $\alpha-\mathrm{Al}(\mathrm{Gd})$ с содержанием Gd $0.51 \%$ (черные области на рис. 2,a) размером порядка $5 \mu \mathrm{m}$, фаза $\mathrm{Al}_{9} \mathrm{Co}_{2}$ (серая фаза на рис. $2, a$ ) и в небольшом количестве фаза $\mathrm{Al}_{3} \mathrm{Ni}$ (светло-серые тонкие иглоподобные кристаллы на рис. 2,a) длиной порядка $10 \mu \mathrm{m}$. Остальное пространство заполнено нерегулярной дисперсной пластинчато-стерженьковой эвтектикой с элементным составом: $\mathrm{Al}_{80.41 \%} \mathrm{Ni}_{3.16 \%} \mathrm{Co}_{14.78 \%} \mathrm{Gd}_{1.65 \%}$ (см. табл. 2). Эвтектика располагается преимущественно в объеме фаз $\mathrm{Al}_{3} \mathrm{Gd}$ и $\mathrm{Al}_{9} \mathrm{Co}_{2}$ (рис. 2,a).

При затвердевании под давлением $3 \mathrm{GPa}$ фазовый состав сплава меняется. Сплав кристаллизуется с формированием двух равновесных фаз: $\alpha$-Al $(\mathrm{Gd})$ и $\mathrm{Al}_{4} \mathrm{CoNi}_{2}$ (см. табл. 1). Первоначально формируются тонкие стержневидные кристаллы фазы $\mathrm{Al}_{4} \mathrm{CoNi}_{2}$ длиной $\sim 100 \mu \mathrm{m}$ и толщиной менее $5 \mu \mathrm{m}$ (рис. $2, b)$, в состав которых входят элементы сплава: $\mathrm{Al}_{70.33} \mathrm{Ni}_{22.96} \mathrm{Co}_{6.71}$ (см. табл. 3). От первичных кристаллов берут начало своего роста дендриты фазы $\alpha$-Al (рис. 2, $b$ ). В со-
Таблица 2. Элементный анализ исходного образца $\mathrm{Al}_{86} \mathrm{Ni}_{2} \mathrm{Co}_{6} \mathrm{Gd}_{6}$

\begin{tabular}{c|c|c|c|c}
\hline \multirow{2}{*}{ Элемент } & \multicolumn{4}{|c}{ at.\% } \\
\cline { 2 - 5 } & $\mathrm{Al}_{3} \mathrm{Gd}$ & $\alpha$ - $\mathrm{Al}(\mathrm{Gd})$ & $\mathrm{Al}_{9} \mathrm{Co}_{2}$ & эвтектика \\
\hline $\mathrm{Al}$ & 76.12 & 99.49 & 82.12 & 80.41 \\
$\mathrm{Ni}$ & - & & - & 3.16 \\
$\mathrm{Co}$ & - & - & 17.88 & 14.78 \\
$\mathrm{Gd}$ & 23.88 & 0.51 & - & 1.65
\end{tabular}

Таблица 3. Элементный анализ образца $\mathrm{Al}_{86} \mathrm{Ni}_{2} \mathrm{Co}_{6} \mathrm{Gd}_{6}$ $\left(3 \mathrm{GPa}, 1500^{\circ} \mathrm{C}\right)$

\begin{tabular}{c|c|c|c}
\hline \multirow{2}{*}{ Элемент } & \multicolumn{3}{|c}{ at.\% } \\
\cline { 2 - 4 } & $\mathrm{Al}_{4} \mathrm{CoNi}_{2}$ & $\alpha$-Al(Gd) & эвтектика \\
\hline $\mathrm{Al}$ & 70.33 & 98.50 & 91.21 \\
$\mathrm{Ni}$ & 22.96 & - & 1.40 \\
$\mathrm{Co}$ & 6.71 & - & 3.14 \\
$\mathrm{Gd}$ & - & 1.50 & 4.24
\end{tabular}

Таблица 4. Элементный анализ образца $\mathrm{Al}_{86} \mathrm{Ni}_{2} \mathrm{Co}_{6} \mathrm{Gd}_{6}$ $\left(7 \mathrm{GPa}, 1500^{\circ} \mathrm{C}\right)$

\begin{tabular}{c|c|c|c|c}
\hline \multirow{2}{*}{ Элемент } & \multicolumn{4}{|c}{ at.\% } \\
\cline { 2 - 5 } & $\mathrm{Al}_{3} \mathrm{Gd}^{*}(\mathrm{Ni} / \mathrm{Co})$ & $\alpha-\mathrm{Al}(\mathrm{Gd})$ & $\begin{array}{c}\text { крупная } \\
\text { эвтектика }\end{array}$ & $\begin{array}{c}\text { мелкая } \\
\text { эвтектика }\end{array}$ \\
\hline $\mathrm{Al}$ & 75.38 & 98.90 & 90.95 & 91.66 \\
$\mathrm{Ni}$ & 2.47 & - & 1.39 & - \\
$\mathrm{Co}$ & 15.62 & - & 5.22 & 1.73 \\
$\mathrm{Gd}$ & 6.17 & 1.10 & 2.45 & 6.61
\end{tabular}

став $\alpha$-Al входит $\mathrm{Gd}$ в количестве $1.5 \%$, это почти в 3 раза больше, чем в исходном образце. Редкоземельные металлы отличаются сравнительно крупными размерами атомов, и поэтому не образуют больших областей растворимости с другими металлами в твердом состоянии, растворимость не сильно повышается и с увеличением температуры. Между собой РЗМ неограниченно растворимы как в жидком, так и в твердом виде. Можем предположить, что основную роль в формировании аномально пересыщенного раствора здесь 

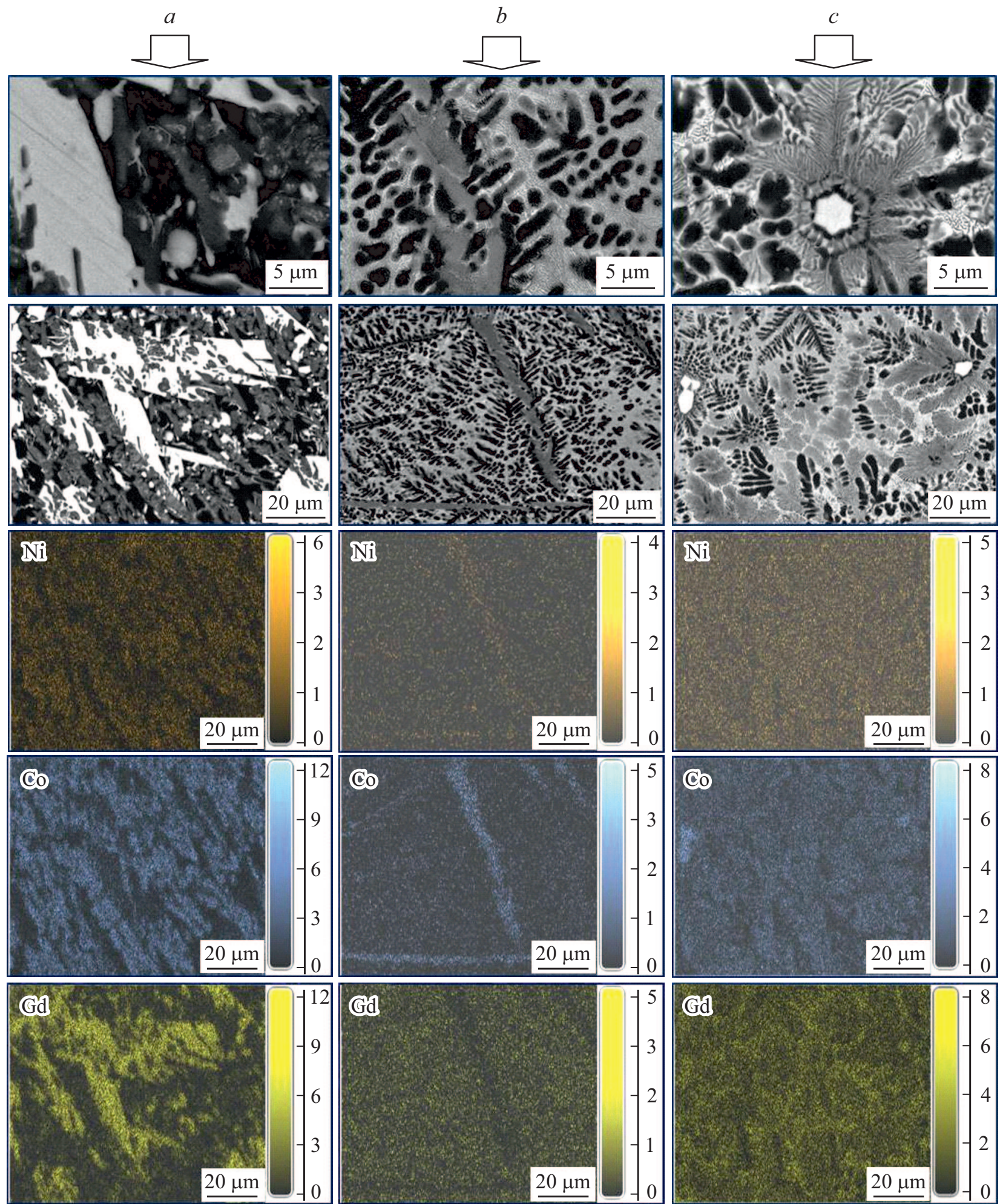

Рис. 2. Микроструктура образцов $\mathrm{Al}_{86} \mathrm{Ni}_{2} \mathrm{Co}_{6} \mathrm{Gd}_{6}$ при различных увеличениях и концентрационные карты распределения элементов в образцах: исходный $(a), 3 \mathrm{GPa}(b), 7 \mathrm{GPa}(c)$.

играет высокое давление. Далее формируется нерегулярная пластинчато-стерженьковая эвтектика $(\alpha-\mathrm{Al}(\mathrm{Gd})+$ и $\mathrm{Al}_{4} \mathrm{CoNi}_{2}$ ) (рис. 2,b). По сравнению с исходным образцом структура, в целом, существенно мельче.
Исследования образца, полученного при охлаждении расплава под давлением $7 \mathrm{GPa}$ показали, что фазовый состав сплава, также как и в случае $3 \mathrm{GPa}$, меняется (см. табл. 1), однако формируются новые фазы, об- 


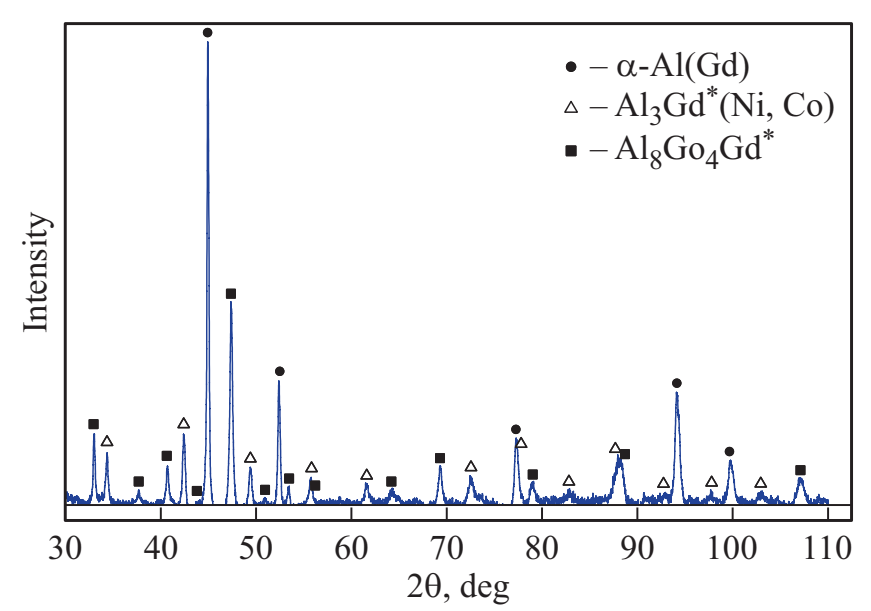

Рис. 3. Рентгенограмма сплава $\mathrm{Al}_{86} \mathrm{Ni}_{2} \mathrm{Co}_{6} \mathrm{Gd}_{6} \quad(7 \mathrm{GPa}$, $\left.1500^{\circ} \mathrm{C}\right)$.

разования сложной геометрической формы. Структура сформированного слитка кристаллическая, мелкодисперсная. По сравнению с исходным образцом структура измельчается так, что размеры первичных кристаллов становятся соизмеримыми с размерами эвтектики. На рис. 3 представлена рентгенограмма образца. Расплав кристаллизуется в несколько стадий. На первом этапе формируется фаза на основе соединения $\mathrm{Al}_{3} \mathrm{Gd}$ (белые кристаллы на рис. 2,c) по типу $\mathrm{Al}_{3} \mathrm{U}$, в состав которой, помимо $\mathrm{Gd}$, входят $\mathrm{Ni}$ и Со - фаза $\mathrm{Al}_{3} \mathrm{Gd}^{*}(\mathrm{Ni}, \mathrm{Co})$. Процентное содержание элементов в фазе: $\mathrm{Al}_{75.38 \%} \mathrm{Ni}_{2.47 \%} \mathrm{Co}_{15.62 \%} \mathrm{Gd}_{6.17 \%}$. Исследования показали, что данная фаза обладает структурой примитивного куба (cР4/2) с параметром решетки $a=4.285 \pm 0.002 \AA$. Известная равновесная фаза $\mathrm{Al}_{3} \mathrm{Gd}$ имеет гексагональную решетку, близкая к ней равновесная фаза $\mathrm{Al}_{2} \mathrm{Gd}-$ кубическую, но она никак не проявляется на дифрактограмме. По-видимому, получен неравновесный вариант фазы $\mathrm{Al}_{3} \mathrm{Gd}$. В благоприятных для роста условиях кристаллы данной фазы стремятся сформироваться в компактные правильные, однородные и изотропные гексагональные шестиугольники размером $\sim 5 \mu$ m или приобрести форму симметричного изотропного дендрита с хорошо развитыми ветвями, образующими лепестки (рис. 2,c). В месте роста кристаллов могут быть немного различающиеся температурные режимы, а также режимы течения питающего раствора и т.п. Поэтому, в зависимости от состояния расплава, вследствие концентрационной, температурной и химической неоднородности кристаллы растут как в длину, так и в ширину, принимая разнообразную форму: форму, близкую к квазикристаллу с осью симметрии пятого порядка, а также форму слегка вытянутых столбиков с шестилучевой симметрией в основе, когда рост происходит преимущественно вдоль оси кристалла. В случаe роста в направлениях, перпендикулярных к оси кристалла, образуются шестиугольные пластинки или шестиугольные звездочки. Грани растущего кристалла покрыты тонкой жидкой пленкой так называемого квазижидкого слоя. Это явление связано с поверхностным „таянием“, которое наблюдается на поверхности многих кристаллических материалов и является разновидностью фазового перехода первого рода. Поверхностное „таяние“ имеет место при температуре ниже точки плавления сплава благодаря менее прочным связям атомов на поверхности кристалла, чем в его глубине. Этот эффект определяет химические взаимодействия между атомами расплава на поверхности кристалла и процессы его роста. Расположение атомов в структуре расплава перед закалкой предопределяет форму роста кристалла и его симметрию. Разумно предположить, что под воздействием высокого давления имеется тенденция возникновения в расплаве кластеров с более плотной упаковкой, чем при атмосферном давлении. Далее формируется аномально пересыщенный твердый раствор $\alpha-\mathrm{Al}(\mathrm{Gd})$ (черные области на рис. 2,c). Содержание $\mathrm{Gd}$ в твердом растворе в два раза больше, чем в исходном образце. Фаза $\alpha-\mathrm{Al}(\mathrm{Gd})$ представляет собой тонко разветвленные дендриты, растущие в радиальном направлении от первичных кристаллов, на рис. 2,c отчетливо видны оси первого и второго порядков с ярко выраженной анизотропией скоростью их роста. На рентгенограмме линии данной фазы в спектре немного смещены в область меньших углов $2 \theta$. После первичных кристаллов и $\alpha$-фазы формируется сферолитная эвтектика: на рис. 2,c отчетливо видно веерное расщепление пластинчатого пакета. Причиной формирования таких неравновесных форм роста, как сферолиты или глобулы, является высокое переохлаждение на фронте кристаллизации расплава [14]. В состав эвтектики входят все элементы сплава (см. табл. 4). Таким образом, есть основания предполагать, что эвтектика представляет собой смесь фаз, состоящую из фазы $\alpha-\mathrm{Al}(\mathrm{Gd})$ и неравновесной фазы $\mathrm{Al}_{3} \mathrm{Gd}^{*}(\mathrm{Ni}, \mathrm{Co})$. Каждая эвтектическая колония растет из своего центра. Зарождение колонии инициирует базовая фаза, характеризующаяся большей долей направленных межатомных связей, т. е. фаза $\mathrm{Al}_{3} \mathrm{Gd}^{*}(\mathrm{Ni}, \mathrm{Co})$. Вторая фаза эвтектики, $\alpha-\mathrm{Al}(\mathrm{Gd})$, растет на базовой как на подложке. В оставшемся пространстве формируется нерегулярная пластинчато-стерженьковая эвтектика (рис. 2,c), в состав которой входят $\mathrm{Al}$, Со и $\mathrm{Gd}$, формируя смесь фаз $\left(\alpha-\mathrm{Al}(\mathrm{Gd})+\mathrm{Al}_{8} \mathrm{Co}_{4} \mathrm{Gd}^{*}\right)$. Фаза $\mathrm{Al}_{8} \mathrm{Co}_{4} \mathrm{Gd}^{*}$ упорядочена по типу известной фазы $\mathrm{Al}_{8} \mathrm{Cr}_{4} \mathrm{Gd}$, но на рентгенограмме линии полученной фазы немного смещены в область бо́льших углов $2 \theta$. Фаза $\mathrm{Al}_{8} \mathrm{Co}_{4} \mathrm{Gd}^{*}$ обладает тетрагональной структурой (tI26/1) с параметрами решетки $a=8.906 \pm 0.003$ и $c=5.150 \pm 0.003 \AA$. Таким образом, выбранные условия задают такую кинетику зарождения и роста фаз центров кристаллизации, при которых образуется дисперсная структура, содержащая метастабильные образования.

Структура полученных под давлением образцов однородная, плотная, не обнаружено усадочных раковин и пор. Исследования показали, что средняя микротвердость образца, полученного, в частности, под давлени- 
ем $7 \mathrm{GPa}$, высокая $(\sim 1700 \mathrm{MPa})$ за счет твердорастворного и дисперсионного упрочнения. Это почти в 2 раза выше, чем в исходном образце.

\section{4. Заключение}

Сочетание высокой скорости затвердевания и механического уплотнения под высоким давлением определило возможность получения сплавов с измельченной структурой и высокой плотностью. Средняя микротвердость образцов, полученных под давлением, высокая за счет твердорастворного и дисперсионного упрочнения. При давлении $7 \mathrm{GPa}$ формируются новые кристаллические фазы: $\mathrm{Al}_{3} \mathrm{Gd}^{*}$ (по типу $\mathrm{Al}_{3} \mathrm{U}$ ), содержащая Co и $\mathrm{Ni}$, со структурой примитивного куба (cР4/2) и $\mathrm{Al}_{8}(\mathrm{Ni} / \mathrm{Co})_{4} \mathrm{Gd}^{*}$ (по типу $\mathrm{Al}_{8} \mathrm{Cr}_{4} \mathrm{Gd}$ ) с тетрагональной структурой (tI26/1) и аномально пересыщенный твердый раствор $\alpha-\mathrm{Al}(\mathrm{Gd})$. Т. о. получены новые фазы фазы высокого давления, область термодинамической устойчивости которых соответствует области высоких давлений. В тех же условиях фазы высокого давления типа $\mathrm{Al}_{3} \mathrm{P} \mathrm{M}^{*}$ синтезировали ранее в сплавах $\mathrm{Al}_{90} \mathrm{Y}_{10}$, $\mathrm{Al}_{87} \mathrm{Ni}_{8} \mathrm{Y}_{5}, \quad \mathrm{Al}_{86} \mathrm{Ni}_{6} \mathrm{Gd}_{4} \mathrm{~Tb}_{2} \mathrm{Er}_{2}$ [11-13]. Ясно, что для подробного изучения полученных новых фаз интересно провести дополнительные исследования.

Представленные результаты показывают принципиальную возможность использования метода затвердевания под давлением для изменения уровня свойств алюминиевых сплавов, применяемых в промышленности, без изменения их химического состава за счет модифицирования структуры и изменения химического состава структурных составляющих образца.

\section{Благодарности}

Электронно-микроскопические исследования выполнены в ЦКП „Центр физических и физико-химических методов анализа, исследования свойств и характеристик поверхности, наноструктур, материалов и изделий“ УдмФИЦ УрО РАН, г. Ижевск.

Авторы выражают искреннюю благодарность И.К. Аверкиеву за помощь в выполнении элементного анализа образцов, а также к.ф.-м.н. В.А. Волкову за помощь в выполнении рентгеноструктурного анализа.

\section{Финансирование работы}

Работа выполнена в рамках государственного задания Министерства образования и науки РФ (проект № 121030100001-3).

\section{Конфликт интересов}

Авторы заявляют, что у них нет конфликта интересов.

\section{Список литературы}

[1] I. Inoue. Prog. Mater. Sci. 43, 365 (1998).

[2] А.М. Глезер, Н.А. Шурыгина. Аморфно-нанокристаллические сплавы. Физматлит, М. (2014). 42 с

[3] Г.Е. Абросимов, А.С. Аронин. ФТТ 59, 11, 2227 (2017).

[4] С.М. Стишов, Л.Г. Хвостанцев, В.Н. Слесарев, С.В. Попова, В.В. Бражкин и др. УФН 178, 10, 1095 (2008).

[5] С.В. Попова, В.В. Бражкин, Т.И. Дюжева. УФН 178, 10 , 1104 (2008).

[6] С.М. Стишов. Фазовые переходы для начинающих. Тровант, М. (2014). 90 с.

[7] В.Ф. Дегтярева. Дисс. докт. физ.-мат. наук. „Структура и устойчивость фаз высокого давления в бинарных сплавах $s p$-металлов". Черноголовка (2002). 205 с.

[8] С.Г. Рассолов, Е.А. Свиридова, В.В. Максимов, В.К. Носенко, И.В. Жихарев, Д.В. Матвеев, Е.А. Першина, В.И. Ткач. Металлофиз. нов. технол. 37, 8, 1089 (2015).

[9] А.П. Шпак, В.В. Маслов, А.Б. Мельник, А.Н. Тимошевский. Металлофиз. нов. технол. 25, 111, 1461 (2003).

[10] В.В. Бражкин. Дисс. канд. физ-мат. наук. „Влияние высокого давления на затвердевание металлических расплавов $(\mathrm{Pb}, \mathrm{In}, \mathrm{Cu}$, двойные сплавы на основе меди)“. М. (1996). $150 \mathrm{c}$.

[11] S.G. Menshikova, V.V. Brazhkin, V.I. Lad'yanov, B.E. Pushkarev, A.A. Suslov. Lett. Mater. 10, 4, 433 (2020).

[12] S.G. Menshikova, V.V. Brazhkin, V.I. Lad'yanov, B.E. Pushkarev. Crystal Growth 524, 125164 (2019).

[13] S.G. Menshikova, I.G. Shirinkina, I.G. Brodova, V.V. Brazhkin, V.I. Lad'yanov, B.E. Pushkarev. J. Crystal Growth 525, 125206 (2019).

[14] И.Г. Бродова, П.С. Попель, Н.М. Барбин, Н.А. Ватолин. Исходные расплавы как основа формирования структурных свойств алюминиевых сплавов. УрО РАН, Екатеринбург (2005). 369 с.

Редактор Т.Н. Василевская 